\title{
JUNG, Vera, Körperlust und Disziplin. Studien zur Fest- und Tanzkultur im 16. und 17. Jahrhundert
}

\section{Christophe Duhamelle}

\section{OpenEdition \\ Journals}

Édition électronique

URL : http://journals.openedition.org/ifha/1196

DOl : 10.4000/ifha. 1196

ISSN : 2198-8943

Éditeur

IFRA - Institut franco-allemand (sciences historiques et sociales)

Référence électronique

Christophe Duhamelle, « JUNG, Vera, Körperlust und Disziplin. Studien zur Fest- und Tanzkultur im 16. und 17. Jahrhundert », Revue de l'IFHA [En ligne], Date de recension, mis en ligne le 01 janvier 2002, consulté le 22 septembre 2020. URL : http://journals.openedition.org/ifha/1196 ; DOI : https://doi.org/10.4000/ ifha. 1196

Ce document a été généré automatiquement le 22 septembre 2020.

(C)IFHA 


\title{
JUNG, Vera, Körperlust und Disziplin. Studien zur Fest- und Tanzkultur im 16. und 17. Jahrhundert
}

\author{
Christophe Duhamelle
}

1 Flanqué de quinze lauriers, un jardin en sucre de 20 mètres de long sur 7 mètres de large constitua un des morceaux de bravoure de la fête d'anniversaire de la duchesse de Brunswick-Lunebourg en 1694 (p. 287) ; l'histoire ne dit pas si tout fut mangé. La prodigalité, en tout cas, constitue un des points communs entre « fêtes du peuple » et " fêtes de cour » dont V.J. se fixe pour objectif de les rassembler sous un même regard. Disons d'emblée que ce travail - une thèse de doctorat effectuée sous la direction de Richard van Dülmen - n'a pas ménagé ses efforts pour accumuler une connaissance parfois encyclopédique (1 700 notes de bas de page) sur la fête et la danse aux XVIe et XVIIe s. Consacré principalement à l'Allemagne, le livre envisage aussi d'autres modèles européens lorsqu'il aborde les fêtes auliques, ce qui se justifiait parfaitement, à condition toutefois d'exprimer cette justification.

On touche là à une première limite de l'ouvrage de V.J. : sa cohérence peine à transparaître. La volonté de parler en même temps des fêtes « populaires » et de celles de « l'élite » se résout ainsi en une simple juxtaposition (voire une énumération) dont le fil conducteur est bien ténu et qui débouche, sans vraiment le démontrer, sur le postulat d'une séparation croissante, au XVIe s., entre les deux cultures. Il semble que cette césure ressortisse davantage du plan du livre lui-même que d'une analyse approfondie des interactions qui sont au cœur de la fête publique. De même, l'articulation entre ce qui est dit de la fête et ce qui l'est de la danse n'est pas nettement marquée.

3 Il est vrai que le choix des sources (essentiellement des descriptions, trop prises comme reflets et non comme créations de sens, et des prescriptions normatives, promotrices plus que révélatrices d'une dichotomie dont on sait qu'elle n'est qu'un élément de pratiques beaucoup plus partagées), justifié par la volonté encyclopédique, mais peu susceptible d'apporter du neuf, ne permettait pas toujours à V.J. de dépasser une 
appréhension sociale un peu massive de la fête. Tel article de Norbert Schindler sur une procession nous en apprend beaucoup plus sur le jeu d'institutions, de pratiques et de concurrences mis en œuvre au cours des festivités qui s'inscrivent toujours dans un contexte. De même, les relations entre la fête, d'une part, et d'autre part la liturgie, les communautés civiques ou la création de mémoire ne font pas véritablement l'objet d'une réflexion.

4 Cet ouvrage riche et savant donne par conséquent parfois l'impression d'effleurer son sujet, dont les implications excèdent la bibliographie, pourtant abondante. Les pages sur la veillée, pour ne prendre qu'un exemple, manquent de densité, de références françaises, de réflexion sur les pratiques économiques, et reproduisent trop fidèlement le discours des autorités. À cette historienne dont la démarche rappelle parfois celle des « manuels de folklore " d'antan et attribue à la "diversité » une fonction plus taxinomique qu'heuristique, on serait donc tenté de rappeler malicieusement un proverbe : qui trop embrasse, mal étreint. 